\title{
Is COVID-19 a turning point for the health workforce?
}

\author{
Fernando Aith ${ }^{1}$, Midalys Castilla Martínez ${ }^{2}$, Malhi Cho ${ }^{3}$, Gilles Dussault ${ }^{4}$, Matthew Harris ${ }^{5}$, \\ Mónica Padilla ${ }^{6}$, Gail Tomblin Murphy ${ }^{7}$, Paul Tomlin ${ }^{8}$ and José M Valderas ${ }^{9}$
}

Suggested citation Aith F, Castilla Martínez M, Cho M, Dussault G, Harris M, Padilla M et al. Is COVID-19 a turning point for the health workforce? Rev Panam Salud Publica. 2020;44;e102. https://doi.org/10.26633/RPSP.2020.102

In 2015, the United Nations issued the Agenda for Sustainable Development Goals,(1) which highlighted the need to ensure healthy lives and promote well-being for all across the lifespan. Goal 3 aims to make sure everyone has access to health and health coverage and, in 2019, the United Nations General Assembly adopted the political declaration of the highlevel meeting on universal health coverage reaffirming that "health is a precondition for and an outcome and indicator of the social, economic and environmental dimensions of sustainable development".(2) The High-Level Commission on Health Employment and Economic Growth identified that investments in the health and social workforce can spur inclusive economic growth.(3)

Achieving Goal 3 requires health services that are accessible (available and affordable), culturally acceptable and that provide quality care by well-trained health workers. The World Health Organization (WHO), however, estimates a worldwide projected shortfall of 18 million health workers by 2030, mostly in low- and lower-middle income countries. Countries at all levels of socioeconomic development face -to varying degrees- difficulties in employment, deployment, retention, and performance of their workforce due to chronic underinvestment in education and training of health workers and the mismatch between education and employment strategies in relation to health systems and population needs.(4)

The Pan American Health Organization/World Health Organization (PAHO/WHO) has a long history of contribution to the development of human resources for health in the Region of the Americas through pioneering actions such as calling for regional action to implement policies for the development of human resources in health in areas such as regulation, education, professional practice, work, and specialized migration, as well as the creation of observatories and the Virtual Campus for Public Health. Its "Strategy on Human Resources for
Universal Access to Health and Universal Health Coverage" (5) offers guidance to countries to progress towards improving the availability, accessibility and quality of their health workforce. Evidence-informed workforce policies are of critical importance in support of strong and resilient health care systems.

In alignment with the priorities set by the Strategy, a special issue of the Pan American Journal of Public Health on "Human resources for Universal Health" was planned at the end of 2019 as a contribution to implementing the vision of the Astana Declaration on primary health care (6), with the goal of stimulating research on three topics: governance, capacity building, and education and training of health workers.

Research can produce actionable evidence for governance on how decision-making, planning, regulation, inter-sectoral and inter-organizational coordination, leadership and management mechanisms are conducive to the design and implementation of workforce policies that respond to the rapidly changing needs of the populations in equitable manner. There is equity in access when all members of a population have the same level and quality of access to health workers, according to need, irrespective of their capacity to pay and without any form of discrimination (social status, ethnic origins, religion, sexual orientation, etc.). Access to health workers is equitable when it is modulated in function of the importance of the need, e.g. urgency, or the severity of the health problem, and when health workers provide the same quality of service to all people who need it.

As regards to capacity building, it is critical to establish the technical and leadership skills that are available at all levels of the policy development and management of the workforce, and to create and sustain supportive management that motivates and enables workers to provide services at the highest level of quality.

We also need more clarity about how to align education and training programs with the needs of health services, so that they

\footnotetext{
Facultad de Salud Pública, Universidade de São Paulo, São Paulo, Brazil

2 Cuban Medical Services, Havana, Cuba

3 Pan American Health Organization, Washington, DC, United States of America

Instituto de Higiene e Medicina Tropical, Universidade Nova, Lisbon, Portugal
} 
equip health workers from their initial training and all along their professional life with relevant competencies.

Then came the COVID-19 pandemic! In a matter of weeks, even days, it did more than all past advocacy efforts to highlight in real time the critical role of health workers, vital to respond to emergencies and disasters. All of a sudden, physicians, nurses, auxiliaries, ambulance staff, and all support personnel became heroes. However, it soon became clear that the commitment demonstrated by health workers was not enough to respond adequately to the crisis. Numerous deficiencies in the management of the health workforce became visible to all, from users of services to political decision-makers. In addition to insufficient numbers of workers overall, the crisis revealed inequities of access due to shortages in certain regions, typically rural, remote and poor. In many countries of the Region, this is compounded by the underutilization of the skills of diverse occupational groups, like nurses and pharmacists, and by an inefficient composition of the workforce, with low ratios of nurses (7) and other personnel to physicians, and of generalists to specialists. It also threw light on the often difficult working conditions of health staff, their low remuneration, and the gaps between what is necessary to provide a good response to the needs of the sick and what is at their disposal. It showed the need for upskilling personnel working in intensive care units, in homes for the aged and the disabled, and physicians and nurses needed training in the use of telemedicine.

Even if this was not news to students of health labor markets, it was a wake-up call for policy-makers and the public. The recognition of these problems is a prerequisite to the introduction of change. So what needs to be done given that COVID-19 has made this problem so obvious? This is where research finds its purpose and applicability and where sound scientific evidence can make a contribution to informing policy-making. The workforce situation needs to be well documented, the causes of its weaknesses understood, and above all, the options to intervene, what works, what does not work, all need to be identified.

Some important questions remain: Will the crisis be a catalyst of policy change? Will governments spend more on health services and their workers? Spending on the health workforce, if done well, is a good investment. The challenge is for countries to develop policies that generate efficiency and effectiveness; planning a more rational balance between community health workers, nurses and physicians; expanding the scope of practice to make the full potential of each cadre available; systematic regulation of education and of practice; and the creation of enabling work environments. The result will not only be better health indicators, but also economic growth.(8) It could also avoid or help mitigate the disastrous economic consequences that the world has experienced as a result of the 2020 public health crisis.

The publication by the Pan American Journal of Public Health of this special issue on human resources for universal health seems timely as it coincides with the International Year of the Nurse and the Midwife and with the landmark publication of the State of the World's Nursing 2020 Report.(9) This issue presents research on the most important resource of health services -its workers. We hope the articles provide valuable experience and evidence that will inform decisions and health policies in the Region going forward and provide impetus to the implementation of the Declaration of Astana.

\section{REFERENCES}

1. United Nations. Sustainable Development Goals. The 2030 Agenda for Sustainable Development. 2015. Available from: https://sustainabledevelopment.un.org/post2015/transformingourworld

2. United Nations, General Assembly. Political declaration of the highlevelmeeting on universal health coverage. Resolution A/RES/74/2,10 October 2019. Available from: https:/ / undocs.org/en/A/RES/74/2

3. World Health Organization. Working for health and growth: investing in the health workforce. Report of the High-Level Commission on health; 2016. Available from: https:/ / www.who.int/hrh/com-heeg /reports/en/

4. World Health Organization. Health workforce. Available from: https://www.who.int/health-topics/health-workforce\#tab=tab_1

5. Pan American Health Organization. Strategy on Human Resources for Universal Access to Health and Universal Health Coverage. Washington DC: PAHO; 2017. Available from: https:// iris.paho.org/bitstream/handle/10665.2/34964/CSP29-10-e. pdf? sequence $=1 \&$ isAllowed $=y$
6. World Health Organization and the United Nations Children's Fund (UNICEF). A vision for primary health care in the 21st century: towards universal health coverage and the Sustainable Development Goals. Geneva: WHO and UNICEF; 2018.

7. Cassiani SHB, Hoyos MC, Barreto MFC, Sives K, da Silva FAM. Distribución de la fuerza de trabajo en enfermería en la Región de las Américas. Rev Panam Salud Publica. 2018;42:e72. https://doi. org/10.26633/RPSP.2018.72

8. WHO Commission on Macroeconomics and Health. Macroeconomics and health: investing in health for economic development / Report of the Commission on Macroeconomics and Health. Geneva: World Health Organization; 2001. Available from: https://apps. who.int/iris/handle/10665/42435

9. State of the World's Nursing 2020: investing in education, jobs andleadership.Geneva:World HealthOrganization;2020.Available from: https://www.who.int/publications-detail/nursing-report2020

\section{APPRECIATION}

The Pan American Journal of Public Health recognizes with appreciation the contributions of the members of the Editorial Committee and authors of this Overview. Their dedication to this issue on human resources for universal health helped make the manuscripts more interesting and more useful to our readers and all others who work to improve the health of the peoples of the Americas. 